Corrigendum: A new class of highly potent, broadly neutralizing antibodies isolated from viremic patients infected with dengue virus

Wanwisa Dejnirattisai, Wiyada Wongwiwat, Sunpetchuda Supasa, Xiaokang Zhang, Xinghong Dai, Alexander Rouvinsky, Amonrat Jumnainsong, Carolyn Edwards, Nguyen Than Ha Quyen, Thaneeya Duangchinda, Jonathan M Grimes, Wen-Yang Tsai, Chih-Yun Lai, Wei-Kung Wang, Prida Malasit, Jeremy Farrar, Cameron P Simmons, Z Hong Zhou, Felix A Rey, Juthathip Mongkolsapaya \& Gavin R Screaton

Nat. Immunol. 16, 171-177 (2015); published online 15 December 2014; corrected after print 27 February and 8 April 2015

In the version of this article initially published, affiliation 3 was incomplete. The correct affiliation 3 is as follows: Graduate Program in Immunology, Department of Immunology, Faculty of Medicine, Siriraj Hospital, Mahidol University, Bangkok, Thailand. The Acknowledgements section was also incomplete. The "Supported by" statement should end "...and the Thailand Research Fund through the Royal Golden Jubilee Ph.D. Program (S.S. and J.M.)." The error has been corrected in the HTML and PDF versions of the article.

\title{
Corrigendum: The kinase Jnk2 promotes stress-induced mitophagy by targeting the small mitochondrial form of the tumor suppressor ARF for degradation
}

Qiao Zhang, Hong Kuang, Cong Chen, Jie Yan, Hanh Chi Do-Umehara, Xin-yuan Liu, Laura Dada, Karen M Ridge, Navdeep S Chandel \& Jing Liu

Nat. Immunol. 16, 458-466 (2015); published online 23 March 2015; corrected after print 20 April 2015

In the version of this article initially published, the staining intensity for the merged fluorescence microscopy did not match that in the singlestaining panels in Figure 1c,e. The panels been replaced with the original staining intensities. The error has been corrected in the HTML and PDF versions of the article.

\section{Erratum: The ubiquitin-modifying enzyme $A 20$ restricts ubiquitination of the kinase RIPK3 and protects cells from necroptosis}

Michio Onizawa, Shigeru Oshima, Ulf Schulze-Topphoff, Juan A Oses-Prieto, Timothy Lu, Rita Tavares, Thomas Prodhomme, Bao Duong, Michael I Whang, Rommel Advincula, Alex Agelidis, Julio Barrera, Hao Wu, Alma Burlingame, Barbara A Malynn, Scott S Zamvil \& Averil Ma Nat. Immunol. 16, 618-627 (2015); published online 4 May 2015; corrected after print 21 May 2015

In the version of this article initially published, the filled circles in Figure $3 \mathrm{~b}$ were incorrectly labeled ' $A 20^{+/ f l} \mathrm{CD} 4-\mathrm{Cre}$ '. The correct label is 'A20 ${ }^{\mathrm{fl} / \mathrm{fl}} \mathrm{CD} 4-\mathrm{Cre}$. The error has been corrected in the HTML and PDF versions of the article.

\section{Erratum: Responsiveness of $B$ cells is regulated by the hinge region of $\lg D$}

Rudolf Übelhart, Eva Hug, Martina P Bach, Thomas Wossning, Marcus Dühren-von Minden, Anselm H C Horn, Dimitrios Tsiantoulas, Kohei Kometani, Tomohiro Kurosaki, Christoph J Binder, Heinrich Sticht, Lars Nitschke, Michael Reth \& Hassan Jumaa Nat. Immunol. 16, 534-543 (2015); published online 6 April 2015; corrected after print 21 May 2015

In the version of this article initially published, the bottom left plot in Figure 3c, the top right plot in Figure 4a, and the third and bottom plots in the left column of Figure 6a were duplicates of other plots in the same figure. Those plots have been replaced and the errors have been corrected in the HTML and PDF versions of the article. 